\title{
Ultraestructura de los huevos de dos mariposas nocturnas de Chile: Ormiscodes socialis y Polythysana cinerascens (Lepidoptera: Saturniidae)
}

\author{
Alfonso Benítez-Mora ${ }^{1}$ \& Tania S. Olivares ${ }^{2}$ \\ 1 Universidad de Concepción. Facultad de Ciencias Naturales y Oceanográficas. Departamento de Zoología. Casilla \\ 160-C, Concepción-Chile; abenitez@udec.cl \\ 2 Casilla 4040 correo 3. Concepción-Chile; tolivare@udec.cl
}

Recibido 13-VI-2003. C Corregido 09-XI-2003. Aceptado 09-VIII-2006.

\begin{abstract}
Egg ultrastructure in two Chilean moths: Ormiscodes socialis y Polythysana cinerascens (Lepidoptera: Saturniidae). The structure and ultra-structure of the eggs from Ormiscodes socialis (Feisthamel) and Polythysana cinerascens (Philippi) are described, considering shape, size, coloring when recently laid, oviposition type and aeropiles (quantity, distribution and proportion) in the micropilar area, among others. The ultra-structure is shown for primary cells, secondary cells, aeropiles and micropiles. A comparative table of the eggs of these species is presented and includes the previously described eggs of Adetomeris microphthalma (Philippi). Myoschilos oblonga Ruiz y Pavón (Santalaceae) is recorded as a new host for P. cinerascens. Rev. Biol. Trop. 54 (4): 1085-1091. Epub 2006 Dec. 15.
\end{abstract}

Key words: Lepidoptera, Saturniidae, egg, ultra-structure, key, Adetomeris microphthalma, Ormiscodes socialis, Polythysana cinerascens, new host.

La Familia Saturniidae reúne en total 18 especies en Chile. Estas mariposas nocturnas se destacan por su coloración y su tamaño que alcanza los $100 \mathrm{~mm}$ de envergadura (Artigas 1994). Esta familia es de importancia económica debido a los hábitos gregarios y fitófagos de sus estados larvales. En muchos de los casos causan daños en el área forestal, aunque ésta es más de tipo secundario, por lo tanto no llegan a considerarse como plagas.

En la obra de Lemaire (2002) se recopilan los datos conocidos de los estados preimaginales en las especias chilenas, mayoritariamente larva y en menor grado pupas y huevos, los cuales comprenden los siguientes autores y años:

Adetomeris erythrops (Blanchard): Larva: Ureta 1942.

Adetomeris microphthalma (Izquierdo): Huevo: Hormazábal y Navarro 1995. Larva: Hormazábal y Navarro 1995.
Cercophana frauenfeldi (Felder): Larva: Ureta 1944.

Cercophana venusta (Walker): Larva: Philippi 1859, Ureta 1944, Wolfe y Balcázar-Lara 1994. Capullo: Philippi 1859.

Cinommata bistrigata Butler: Larva: Ureta 1943.

Microdulia mirabilis Rothschild: Capullo: Ureta 1944.

Neocercophana philippi Izquierdo: Huevo, larva, pupa y capullo: Ureta 1944.

Ormiscodes amphinome (Fabricius): Larva: Silva-Figueroa 1917. Pupa: Silva-Figueroa 1917. Complejo hipofaríngeo: Parra et al. 1985.

Ormiscodes socialis (Feisthamel, 1839). Larva: Navarro y Rodríguez 1998. Pupa: Navarro y Rodríguez 1998. 
Polythysana apollina Felder y Rogenhofer: Larva: Ureta 1943.

Polythysana cinerascens (Philippi): Larva: Philippi, Angulo y Weigert 1974. Pupa: Angulo y Weigert 1974.

Polythysana rubrescens (Blanchard): Larva: Ureta 1943.

Exceptuando A. microphthalma y de $N$. philippi, se desconocen totalmente los huevos. Por esto, este informe inicia un estudio detallado de todos los huevos de los satúrnidos chilenos para su identificación.

\section{MATERIALES Y MÉTODOS}

El material utilizado para realizar las descripciones se obtuvo a partir de hembras recolectadas para ambas especies, las que se mantuvieron en cámaras de crianza hasta que ovipusieron, además de huevos colectados en Pinus pinaster Aiton y Myoschilos oblonga Ruiz y Pavón. La descripción del huevo de A. microphthalma se obtuvo de Hormazábal y Navarro 1995. Los huevos que se obuvieron se analizaron bajo lupa estereoscópica Carl Zeiss y fotografiados en Microscopio Electrónico de Barrido, Autoscanning ETEC de la Universidad de Concepción, según la técnica Angulo y Olivares (1991).

Todo el material se encuentra depositado en las colecciones científicas de la Universidad de Concepción, Concepción (UCCC).

\section{RESULTADOS}

A continuación se describen las dos especies y se entrega un cuadro comparativo
(Cuadro 1), incluyendo además a la especie $A$. microphthalma.

$$
\text { O. socialis }
$$

(Feisthamel, 1839)

Sinónimos y combinaciones:

Bombyx socialis Feisthamel, 1839

Dirphia angulifera Walker, 1855

Thauma ribesii (H. Edwards, 1874)

O. socialis grisea Ureta, 1957

Huevo: Los huevos tienen forma cónica (Fig. 1), no presentan costras, son de color verde cuando recién ovipuestos, con mancha rojiza en la zona polar (Fig. 11). Ovipostura en grupos, unos sobre otros, adosados al sustrato por una sustancia cementante. Diámetro $1.4 \mathrm{~mm}$, altura $1.9 \mathrm{~mm}$. Aeropilas en región lateral del cuerpo (Fig. 2). Área micropilar ubicada en la región polar. Celdas primarias de 12, secundarias $15(n=5)$ (Fig. 3). Proporción área micropilar 12/15 ó 1:1.25. Roseta primaria dispuesta en el mismo plano que la secundaria (Fig. 4). Parte más gruesa de celda primaria terminada en punta, destaca una celda de la mitad de tamaño que las otras (Fig. 3). Celdas secundarias el doble de largo y ancho, terminadas en punta. Cinco micropilas en el centro de área micropilar, dispuestas en relieve sobre el plano de la roseta primaria (Fig. 5).

Material examinado: 118 huevos, Chile, VIII Región, Prov. de Concepción, Concepción, Barrio universitario, Universidad de Concepción, vii/2001, H. Moyano Coll. (UCCC).

Hospederos: Pinus radiata D. Don, Nothofagus obliqua (Mirbel), Drimys winteri J.R. et G. Forster, Luma apiculata DC, Cryptocaria alba Molina, Proustia ilicifolia Hook. et Arn. (Angulo et al. 2004). 

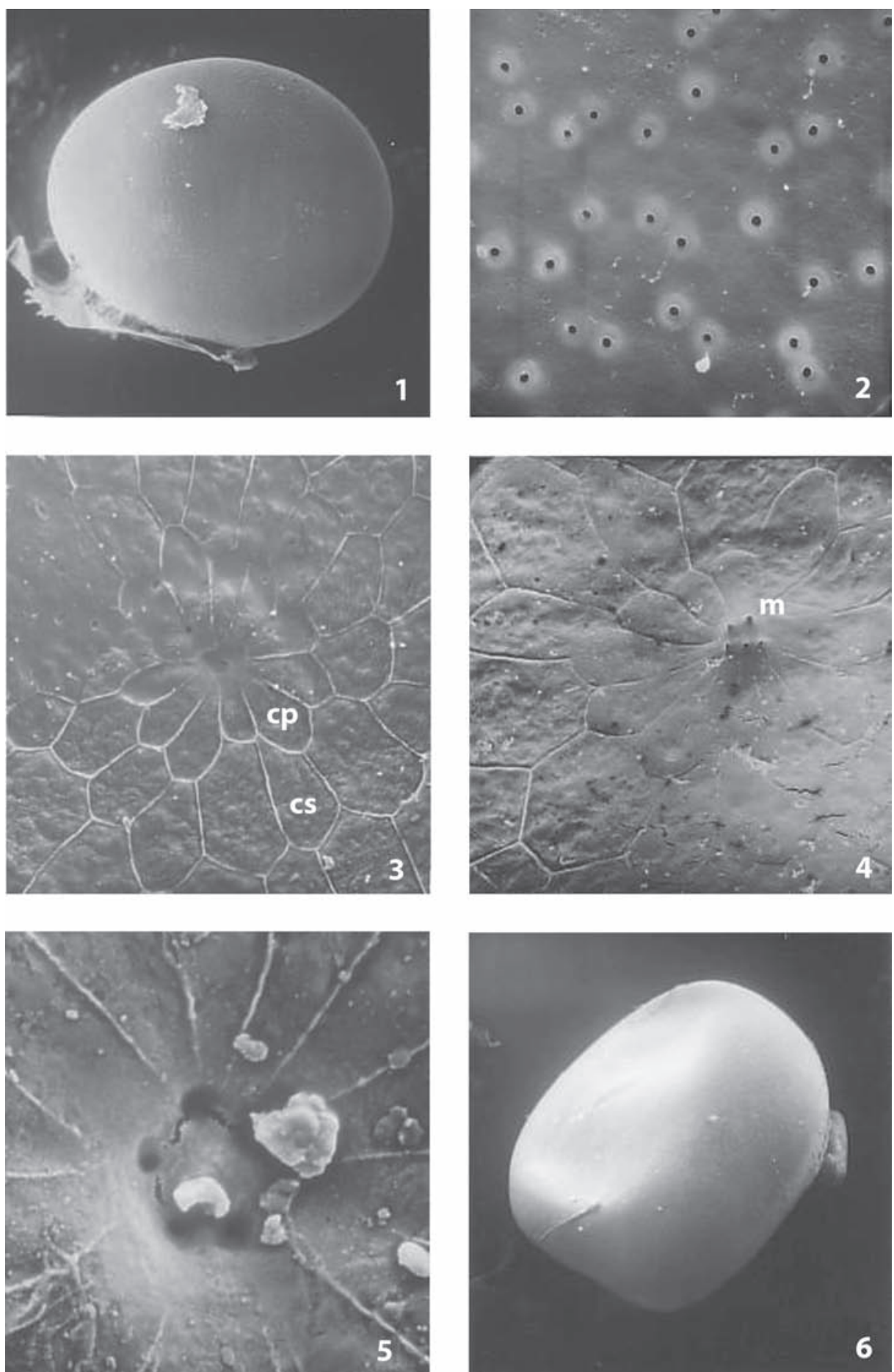

Figs. 1-5. O. socialis. 1. Vista general. 2. Aeropilas. 3. Área micropilar. 4. Roseta primaria. 5. Micropilas. ae: aeropilas; cp: celdas primarias; cs: celdas secundarias; m: micropilas. Fig. 6. P. cinerascens, Vista general.

Figs. 1-5. O. socialis. 1. General view. 2. Aeropiles. 3. Micropilar area. 4. Primary cell. 5. Micropiles. ae: eeropilas; cp: primary cells; cs: secundary cells; m: micropiles. Fig. 6. P. cinerascens, General view. 
CUADRO 1

Cuadro comparativo de los huevos de las tres especies de satúrnidos

TABLE 1

Comparative table of eggs in three Chilean Saturnid species

\begin{tabular}{|c|c|c|c|}
\hline Carácter taxonómico & Ormiscodes socialis & Polythysana cinerascens & Adetomeris microphthalma \\
\hline Costas & Ausentes & Ausentes & $\begin{array}{l}\text { Presentes, sólo visibles a } \\
\text { gran aumento ( } 900 \mathrm{X})\end{array}$ \\
\hline Forma del huevo & Cónico & $\begin{array}{l}\text { Subesférico aplastado } \\
\text { lateralmente }\end{array}$ & Subesférico \\
\hline $\begin{array}{l}\text { Color recién } \\
\text { ovipuestos }\end{array}$ & $\begin{array}{l}\text { Verde con mancha rojiza en la } \\
\text { zona polar }\end{array}$ & $\begin{array}{l}\text { Lateralmente castaño oscuro, } \\
\text { banda blanca meridional, } \\
\text { región polar blanca con } \\
\text { mancha castaño claro al } \\
\text { centro }\end{array}$ & verde \\
\hline Tipo ovipostura & En grupos, unos sobre otros & En hilera, juntos & En hilera o en grupos \\
\hline Tamaño & 1.4 mm diámetro; 1.9 alto & 1.52 mm diámetro; 2.01 alto & 0.6 mm diámetro; 1.7 alto \\
\hline $\mathrm{N}^{\mathrm{o}}$ celdas primarias & 12 & 14 y 15 & 9 a 10 \\
\hline $\mathrm{N}^{\circ}$ celdas secundarias & 15 & 17 y 20 & 15 a 16 \\
\hline $\begin{array}{l}\text { Proporción área } \\
\text { micropilar }\end{array}$ & $1: 1.25$ & $1: 1.2$ y $1: 1.4$ & $1: 1.6$ \\
\hline $\begin{array}{l}\text { Características de las } \\
\text { celdas }\end{array}$ & $\begin{array}{l}\text { Parte más gruesa de celda } \\
\text { primaria terminada en punta, } \\
\text { destaca una celda de la mitad } \\
\text { de tamaño que las otras. } \\
\text { Celdas secundarias el doble } \\
\text { de largo y ancho, terminadas } \\
\text { en punta }\end{array}$ & $\begin{array}{l}\text { Parte más gruesa de celda } \\
\text { primaria terminada en punta, } \\
\text { todas de igual tamaño. } \\
\text { Celdas secundarias gruesas } \\
\text { y cortas generalmente de } \\
\text { menor tamaño que las celdas } \\
\text { primarias }\end{array}$ & $\begin{array}{l}\text { La parte más gruesa de la } \\
\text { celda primaria redondeada, } \\
\text { todas de igual tamaño. } \\
\text { Celdas secundarias } \\
\text { terminadas en punta, igual } \\
\text { tamaño que las primarias }\end{array}$ \\
\hline $\begin{array}{l}\mathrm{N}^{\circ} \text { micropilas en el } \\
\text { área micropilar }\end{array}$ & Cinco & Siete & Una \\
\hline $\begin{array}{l}\text { Distribución de las } \\
\text { micropilas }\end{array}$ & $\begin{array}{l}\text { Dispuestas en relieve sobre el } \\
\text { plano de la roseta primaria }\end{array}$ & $\begin{array}{l}\text { Dispuestas en una superficie } \\
\text { hundida bajo el plano de la } \\
\text { roseta primaria }\end{array}$ & Formando una cavidad \\
\hline
\end{tabular}

\section{P. cinerascens \\ (Philippi)}

Sinónimos y combinaciones:

Attacus cinerascens (Philippi, 1859)

Attacus andromeda (Philippi, 1859)

P. edmondsii Butler, 1882

P. cinerascens f. latchami Ureta 1943
Huevo: Forma subesférica, aplastado lateralmente (Fig. 6). No presenta costas. Lateralmente castaño oscuro, atravesado meridionalmente por una banda color blanco, región polar blanca con mancha castaño claro al centro (Fig. 12). Ovipostura en hilera, juntos, adosados al sustrato por la región lateral mediante una sustancia cementante. Diámetro 
$1.52 \mathrm{~mm}$, altura $2.01 \mathrm{~mm}$. Aeropilas en región lateral del cuerpo (Fig. 7). Área micropilar ubicada en la región polar. Celdas primarias de 14 a 15, secundarias 17 y 20, cuando son 14 celdas primarias hay 17 secundarias y cuando son 15 primarias hay 20 secundarias, sin embargo es mucho más abundante la relación 14 primarias 17 secundarias ( $\mathrm{n}=5$ ) (Fig. 8). Proporción área micropilar más abundante 14/17 ó 1:1.21. Roseta primaria dispuesta en el mismo plano que la secundaria. Parte más gruesa de celda primaria terminada en punta (Fig. 9). Celdas secundarias gruesas y cortas, generalmente de menor tamaño que las celdas primarias. Siete micropilas en el centro de área micropilar, dis- puestas una superficie hundida bajo el plano de la roseta primaria (Fig. 10).

Material examinado: 257 huevos, Chile, VIII Región, Prov. de Concepción, Concepción, s/d, 28/ix/1998, L. A. Cerda Coll. (UCCC).

Hospedero: Myoschilos oblonga Ruiz y Pavón. Nuevo registro. Se registra como nuevo hospedero $M$. oblonga Fam.: Santalaceae, conocido comúnmente como "Codocoypu”, "Orocoipo" о "Codocoipo". Habita lugares húmedos, desde el Aconcagua hasta Chiloé. Especie chilena. Bastante frecuente (Hoffmann 1997).

\section{Clave para separar los huevos de las tres especies de Saturnidae con base en los caracteres de cantidad de micropilas, forma y color y cuando recién ovipuestos}

Una micropila

Adetomeris microphthalma

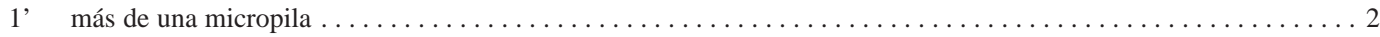

2(1) Huevo subesférico. Micropilas dispuestas en una superficie hundida bajo el plano de la roseta primaria. Cuando recién ovipuesto lateralmente castaño-oscuro, atravesado meridionalmente por una banda color blanco a castaño-claro que llega a la región polar, región polar blanca a castaño-claro con mancha castaño-oscuro en el centro. Ovipostura en hilera, adosado por la región lateral del huevo, juntos. $1.52 \mathrm{~mm}$ diámetro por $2.01 \mathrm{~mm}$ de alto. 14 a 15 celdas primarias y 17 ó 20 secundarias; cuando son 14 celdas primarias van acompañadas de 17 secundarias y cuando son 15 van acompañadas por 20, siendo más abundante la relación 14/17. Celdas secundarias gruesas y cortas, generalmente de menor tamaño que las celdas primarias. Siete micropilas $\ldots \ldots \ldots \ldots \ldots \ldots \ldots \ldots \ldots \ldots \ldots \ldots \ldots$ cinerascens

2' Huevo cónico. Micropilas dispuestas en relieve sobre el plano de la roseta primaria. Cuando recién ovipuesto verde con mancha rojiza en la zona polar. Ovipostura en grupos, adosados por la zona polar del huevo, unos sobre otros. 1.4 mm de diámetro por $1.9 \mathrm{~mm}$ de alto. 12 celdas primarias y 15 celdas secundarias, siempre en esta relación. Celdas secundarias el doble de largo y ancho que las celdas primarias. Cinco micropilas. . . . . . . . . . . . O. socialis

\section{DISCUSIÓN}

Todos los huevos carecen de costas. Los huevos de las especies estudiadas presentaron diferencias en la coloración y la ovipostura. La ovipostura se realiza en hileras o en grupos, adosados por una sustancia cementante. Existe variación en el número de las celdas primarias y secundarias entre cada una de las especies, que va desde una relación de 1: 1.2 en P. cinerascens a 1:1.16 en A. microphthalma. Existen diferencias en el número y distribución de las micropilas, que van desde una en
A. microphthalma a siete en $P$. cinerascens. El tamaño de los huevos varía desde 0.6 a 1.52 mm de diámetro y de 1.7 a $2.01 \mathrm{~mm}$ de alto en las tres especies estudiadas, presentando el menor tamaño el huevo de A. microphthalma y el de mayor tamaño el de $P$. cinerascens. Existe una variación intraespecífica a nivel de las celdas primarias y celdas secundarias. Para la clave de los huevos se incluyeron tres especies, por lo que aún resta incluir, cuando se conozcan, los huevos de las quince especies restantes. $M$. oblonga es un nuevo hospedero de la especie $P$. cinerascens. 

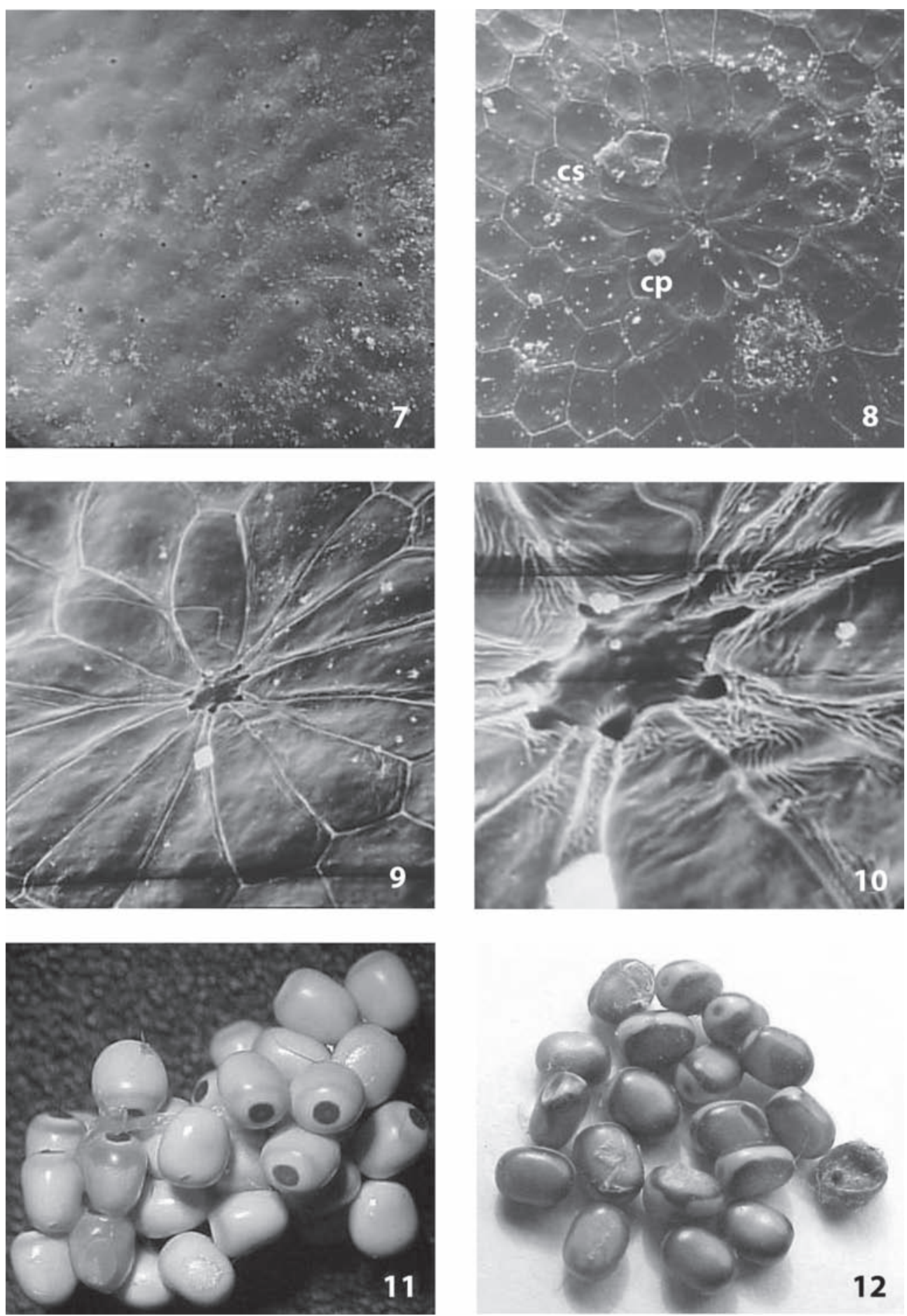

Figs. 7-10. P. cinerascens. 7. Aeropilas. 8. Área micropilar. 9. Roseta primaria. 10. Micropilas. ae: aeropilas; cp: celdas primarias; cs: celdas secundarias; m: micropilas. Fig. 11. Huevos de O. socialis. Fig. 12. Huevos de P. cinerascens.

Figs. 7-10. P. cinerascens. 7. Aeropiles. 8. Micropilar area. 9. Primary cell. 10. Micropiles. ae: eeropilas; cp: primary cells; cs: secundary cells; m: micropiles. Fig. 11. Eggs of $O$. socialis. Fig. 12. Eggs of P. cinerascens. 


\section{AGRADECIMIENTOS}

Los autores agradecen a Hugo H. Moyano y Luis Cerda por la donación del material para realizar el presente trabajo. Nuestro agradecimiento y reconocimiento, en forma especial, a Andrés O. Angulo, por sus sugerencias y críticas al trabajo.

\section{RESUMEN}

Se describe la estructura y ultraestructura de los huevos de las especies Ormiscodes socialis (Feisthamel) y Polythysana cinerascens (Philippi), considerando la forma, tamaño, color, tipo de ovipostura, y aeropilas (cantidad, distribución y proporción) en el área micropilar, entre otros. La ultraestructura es mostrada a través de las celdas primarias, celdas secundarias, aeropilas y micropilas; además se incluye a la especie ya descrita Adetomeris microphthalma (Philippi) y se confecciona un cuadro comparativo para los huevos de estas especies. Se registra como nuevo hospedero de P. Cinerascens a Myoschilos oblonga Ruiz y Pavón (Santalaceae).

Palabras clave: Lepidoptera, Saturniidae, huevos, ultraestructura, clave, Adetomeris microphthalma, Ormiscodes socialis, Polythysana cinerascens, nuevo hospedero.

\section{REFERENCIAS}

Angulo, A.O. \& G.T. Weigert. 1974. Estados preimaginales de Polythysana cinerascens (Phil.) (Lepidoptera: Saturniidae). Bol. Soc. Biol. Concepción 47: 145-150.

Angulo, A.O., C. Lemaire \& T.S. Olivares. 2004. Catálogo crítico e ilustrado de las especies de la familia saturniidae en Chile (Lepidoptera: Saturniidae). Gayana 68: 20-42.

Angulo, A.O. \& T.S. Olivares. 1991. Microestructura del exocorion en huevos de algunas especies de nóctuidos (Lepidoptera: Glossata: Noctuidae). Ans. Ins. Pat. Ser. Cs. Nats. 20: 95-100.
Artigas, J.N. 1994. Entomología económica. Insectos de interés agrícola, forestal, médico y veterinario (nativos, introducidos y susceptibles de ser introducidos). Universidad de Concepción, Concepción, Chile 2: 943 p.

Hoffmann, A.E. 1997. Flora silvestre de Chile, zona araucana, árboles, arbustos y enredaderas leñosas. Fundación Claudio Gay, Santiago, Chile. 258 pp.

Hormazábal, M.E. \& M.E. Navarro. 1995. Descripción del huevo, larva en primer estadío y genitalia de Adetomeris microphthalma (Ph.) (Lepidoptera: Saturniidae). Gayana Zool. 59: 41-46.

Lemaire, C. 2002. The Saturniidae of America. Les Saturniidae Americains. Hemileucinae (= Attacinae). Goecke \& Evers Antiquariat, Keltern, Deutschland. Part 1-3. 1388 p. + 214 plates.

Navarro, M.E.\& M.A. Rodríguez. 1998. Ormiscodes socialis socialis (Feisthamel, 1839): descripción de los estados postembrionales (Lepidoptera: Saturniidae). Guayana Zool. 62: 37-44.

Parra, L.E., A.O. Angulo \& C. Jana-Sáenz. 1985. Biología y estados inmaduros de dos mariposas saturnidas chilenas (Lepidoptera: Saturniidae). Caracteres diagnósticos diferenciales específicos. Bol. Soc. Biol. Concep. Chile 56: 131-139.

Philippi, R.A. 1859. Descripción de algunas nuevas especies de mariposas chilenas, principalmente en la Provincia de Valdivia. An. Univ. Chile 16: 10881114.

Silva-Figueroa, C. 1917. La Dirphia amphimone, (F.) Berg i sus parásitos. Bol. Mus. Nac. Chile. 10: 105-128.

Ureta, E. 1942. Revisión de las especies del género Automeris Hbn. (Saturniidae). Bol. Mus. Nac. Chil. 20: 51-80 +4 lám.

Ureta, E. 1943. Revisión del género Polythysana Wkr. (Saturniidae). Bol. Mus. Nac. Chile 21: 55-70.

Ureta, E. 1944. La familia Saturniidae (Heterocera) en Chile. III Parte. Bol. Mus. Nac. Chile 22: 49-64.

Wolfe, K.L. \& M.A. Balcázar-Lara. 1994. Chile’s Cercophana venusta and its immature stages (Lepidoptera: Cercophanidae). Trop. Lepid. 5: 35-42. 
